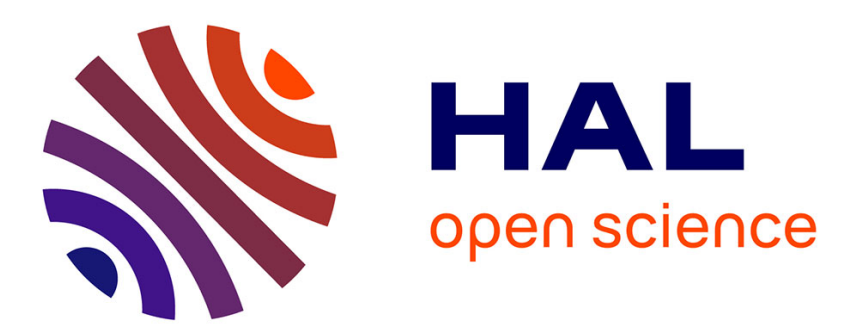

\title{
Experimental investigation of an open thermochemical process operating with a hydrate salt for thermal storage of solar energy: Local reactive bed evolution
}

Benoit Michel, Nathalie Mazet, Pierre Neveu

\section{- To cite this version:}

Benoit Michel, Nathalie Mazet, Pierre Neveu. Experimental investigation of an open thermochemical process operating with a hydrate salt for thermal storage of solar energy: Local reactive bed evolution. Applied Energy, 2016, 180, pp.234-244. 10.1016/j.apenergy.2016.07.108 . hal-01365782

\author{
HAL Id: hal-01365782 \\ https://hal.science/hal-01365782
}

Submitted on 13 Sep 2016

HAL is a multi-disciplinary open access archive for the deposit and dissemination of scientific research documents, whether they are published or not. The documents may come from teaching and research institutions in France or abroad, or from public or private research centers.
L'archive ouverte pluridisciplinaire $\mathbf{H A L}$, est destinée au dépôt et à la diffusion de documents scientifiques de niveau recherche, publiés ou non, émanant des établissements d'enseignement et de recherche français ou étrangers, des laboratoires publics ou privés. 


\title{
Experimental investigation of an open thermochemical process operating with a hydrate salt for thermal storage of solar energy: local reactive bed evolution
}

\author{
Benoit Michel ${ }^{\mathrm{a}, *}$, Nathalie Mazet $^{\mathrm{a}}$, Pierre Neveu $^{\mathrm{a}, \mathrm{b}}$ \\ ${ }^{a}$ PROMES-CNRS, Tecnosud, Rambla de la thermodynamique, 66100 Perpignan, France \\ ${ }^{b}$ Université de Perpignan Via Domitia, 52 Av. Paul Alduy, 66860 Perpignan, France
}

\begin{abstract}
Their high energy density and low heat losses between storage and recovery times make thermochemical processes a promising way to achieve long-term (seasonal) storage. Among the available reactor configurations, open systems using a packed bed of reactive solid are simple and efficient. This paper reports on the local operation and reactive bed behavior of such systems. Mass transfer changes within the reactive bed, which is the main limitation of such systems, was investigated using several state variables (reaction advancement, pressure drop across the salt bed and bed temperatures). Results from two experimental set-ups were analyzed: a small bench for mass transfer characterization, and a prototype at a larger scale. Both used $\mathrm{SrBr}_{2} / \mathrm{H}_{2} \mathrm{O}$ as reactive pair.

A salt bed temperature analysis evidenced a reaction front moving within the reactive layer from the moist air inlet to its outlet. A mass transfer study showed marked changes in the reactive bed permeability during the reaction (by one order of magnitude) and with the reactive bed density (from $10^{-9}$ to $10^{-12} \mathrm{~m}^{2}$ when density range from 300 to $600 \mathrm{kWh} \cdot \mathrm{m}^{-3}$ ). During the reaction an asymmetric time course of the bed permeability was also highlighted: as $f(X)$ in dehydration and $\mathrm{f}(1 / \mathrm{X})$ in hydration.
\end{abstract}

Keywords: Thermochemical process, open sorption process, solid-gas reaction, thermal storage, seasonal storage, solar energy

* Corresponding author

E-mail: benoit.michel@univ-savoie.fr (B. Michel)

Preprint submitted to Elsevier

July 7, 2016 


\section{Nomenclature}

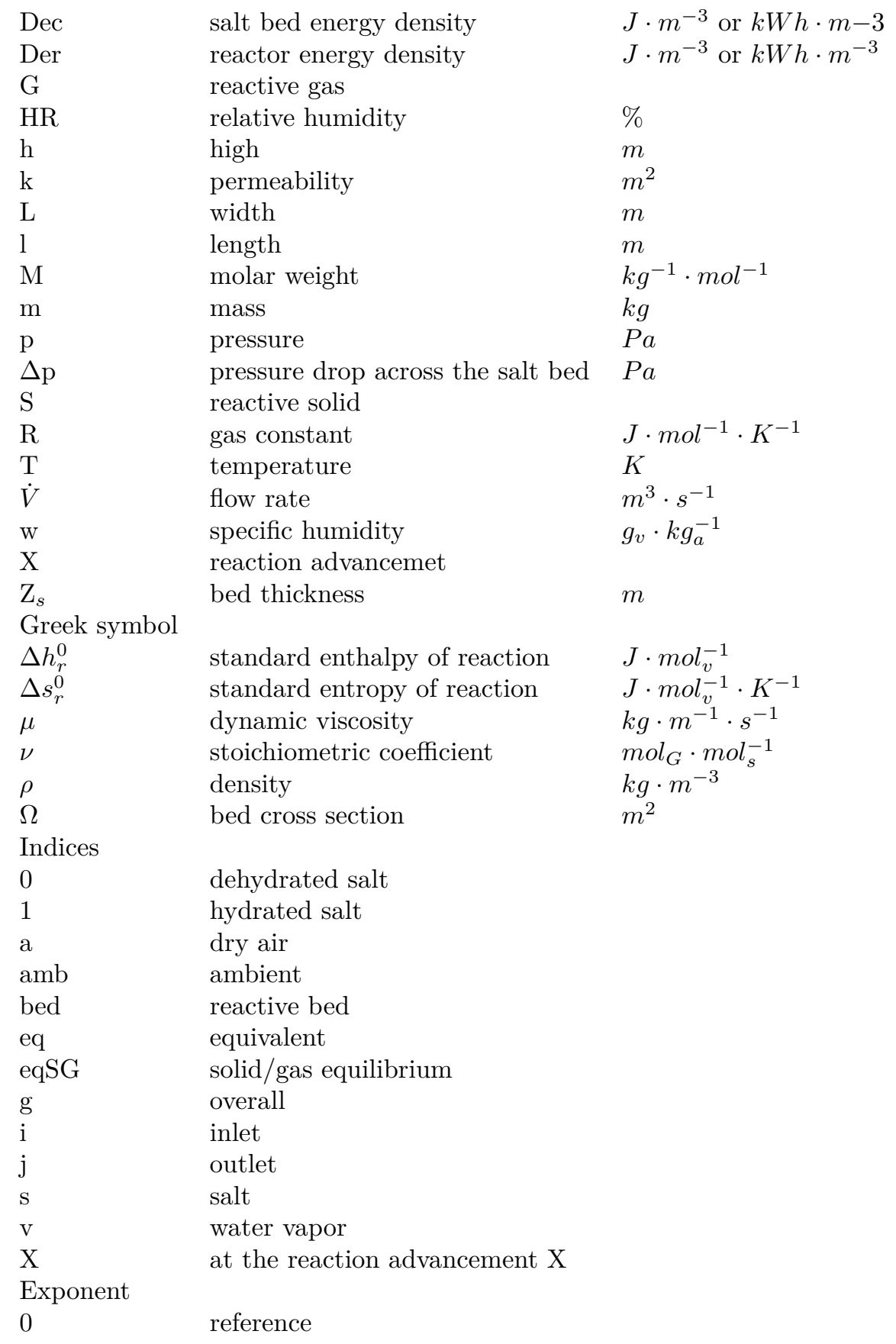




\section{Introduction}

Energy demand for buildings accounts for $25 \%$ of total energy consumption worldwide and $40 \%$ in Europe. Most of this energy is used for space heating: 53\% worldwide and about $80 \%$ in Europe [1]. The increasing scarcity and cost of fossil fuels, and incentives to reduce greenhouse gas emissions, have led to a growing interest in ways to reduce energy consumption, in particular in the residential sector. The use of renewable energies, and in particular solar energy for household applications, is one major way to decrease energy consumption and greenhouse gas emissions in the residential sector generally. Unfortunately, the solar resource is intermittent, and there is a mismatch between the supply and demand periods. Accordingly, to optimize the use of solar energy, especially for house heating, it would useful to be able to conserve excess solar energy delivered in summer by long-term thermal storage (3-6 months).

Interest in seasonal storage for residential applications is currently rising, and several studies have been carried out [2-5]. Such storage systems must lose as little heat as possible between summer and winter, and be as compact as possible i.e. have the highest possible energy density. Among available processes, thermochemical storage is regarded as the solution with the greatest long-term potential [3, 6-9]. It offers the advantage of negligible heat losses between storage and recovery periods because the energy is stored as chemical potential, and the sensible heat of the elements is low. Moreover it offers a high storage density (about 200 to $500 \mathrm{kWh} \cdot \mathrm{m}^{-3}$ ). In comparison, energy density is about $90 \mathrm{kWh} \cdot \mathrm{m}^{-3}$ for latent storage and about $54 \mathrm{kWh} \cdot \mathrm{m}^{-3}$ for sensible heat storage (water, $\Delta \mathrm{T}=70^{\circ} \mathrm{C}$, heat losses of $25 \%[10]$ ).

Thermochemical storage involves a reversible chemical reaction between a solid and a gas:

$$
S_{0}+\nu G \Longleftrightarrow S_{1}+\nu \Delta h_{r}^{0}
$$

This thermochemical process is a monovariant system; the equilibrium conditions $\left(\mathrm{p}_{e} q S G\right.$, $\mathrm{T}_{e} q S G$ ) of the solid/gas reaction follow the Clausius-Clapeyron relation (eq 2). Thus assuming the reactive gas behaves as a perfect gas, we can write:

$$
\ln \left(\frac{p_{e s S G}}{p^{0}}\right)=-\frac{\Delta h_{r}^{0}}{R T_{e q S G}}+\frac{\Delta s_{r}^{0}}{R}
$$

where $\Delta h_{r}^{0}$ and $\Delta s_{r}^{0}$ are respectively the standard enthalpy and entropy of the solid/gas reaction (per mol of gas) and $p^{0}$ is the reference pressure (1 bar). The synthesis (or hydration) of the solid $\mathrm{S}_{1}$ is exothermic (heating or heat recovery period); its decomposition (or dehydration) requires a heat input (storage period).

Numerous salt hydrates have been proposed in the literature for thermochemical storage [11-15]. The solid/gas pair studied in this paper is the hydrate/water pair strontium bromide $/ \mathrm{H}_{2} \mathrm{O}$ :

$$
<\mathrm{SrBr}_{2} \cdot 1 \mathrm{H}_{2} \mathrm{O}>+5\left(\mathrm{H}_{2} \mathrm{O}\right) \Longleftrightarrow<\mathrm{SrBr}_{2} \cdot 6 \mathrm{H}_{2} \mathrm{O}>+5 \Delta h_{0}^{r}
$$

$<\mathrm{SrBr}_{2} \cdot 1 \mathrm{H}_{2} \mathrm{O}>$ and $<\mathrm{SrBr}_{2} \cdot 6 \mathrm{H} 2 \mathrm{O}>$ are respectively the dehydrated $\left(\mathrm{S}_{0}\right)$ and hydrated $\left(S_{1}\right)$ salts and the reactive gas $(\mathrm{G})$ is water. Mauran et al. [16] measured the standard enthalpy and entropy of the reaction: $\Delta h_{r}^{0}=67400 \mathrm{~J} / \mathrm{mol}_{v}$ and $\Delta s_{r}^{0}=175 \mathrm{~J} / \mathrm{K} / \mathrm{mol}_{v}$. // 
This reactive pair had already been found promising for low-temperature thermochemical processes for thermal storage and house-heating applications, especially using solar energy $[8,9,13,16]$. Its equilibrium conditions allow its dehydration with solar energy (temperature under $80^{\circ} \mathrm{C}$ ) and allows temperatures restitutions compatible with house heating (up to $30^{\circ} \mathrm{C}$ ) during hydration. Its ideal energy storage density is very high: $629 \mathrm{kWh} \cdot \mathrm{m}^{-3}$ (referring to its bulk density, $2390 \mathrm{~kg} \cdot \mathrm{m}^{-3}$, and molar mass of hydrated salt, $0.3555 \mathrm{~kg} \cdot \mathrm{mol}^{-1}$ ) [17]. Note that the energy density of the reactive bed (Dec) is defined by the following relation:

$$
D e c=\frac{\rho_{\text {bed }} \cdot \nu \cdot \Delta h_{0}^{r}}{M_{s}}
$$

A prior small-scale experiment [18] showed its suitability for seasonal storage applications. In particular, high reactive bed energy densities were reached (up to $400 \mathrm{kWh} \cdot \mathrm{m}^{-3}$ of reactive bed volume).

For thermochemical systems, the simplest and most efficient reactor configuration has to be defined in order to reduce manufacturing, operating and maintenance costs. Various solid/gas reactor configurations have been proposed in the literature [19-21], and three main technologies emerge: packed bed, moving bed (screw or rotary reactor, gravity assisted bulk flow, etc.) and fluidized reactor. A porous packed bed of reactive solid is generally considered to be the most appropriate reactor configuration for hydration/dehydration [21], and has been used in several thermochemical systems [8, 22-24]. This simple, cheap reactor configuration was selected for this study.

Thermochemical reactors using a hydrate/water pair can operate in two different modes: closed or open. Both have been studied in the literature, both numerically and experimentally [21, 25]. In closed thermochemical systems [8, 22, 24, 26-28], the salt reacts with pure water vapor at fairly low pressure. This type of operation well below atmospheric pressure generates strong technological constraints for reactor design, and any leakage strongly reduces reactor performance [29]. This reactor configuration is therefore unsuitable for large-scale storage applications.

In an open system $[5,18,30-36]$, the reactive solid bed is permeated by a moist air flow at atmospheric pressure, allowing simpler and cheaper reactor design. It also requires no evaporator/condenser or water tank, which increases compactness. The feasibility of open systems has been studied in recent research, and they seem promising for seasonal storage applications [37, 38]. However, most of these studies have addressed overall performance of the storage process [5, 34, 36], and none addresses the local analysis of a thermochemical reactor for storage systems. Yet, knowledge of how the heat and mass transfer (which conditions the reaction power) change in the reactive porous bed, is essential for designing and managing thermochemical systems [21, 39].

This work thus set out to gain a fuller understanding of how the reactive bed behaves locally during reactions. It analyzes the mass transfer and chemical changes in the bed. Several relevant state variables are considered: two overall variables (overall reaction advancement and pressure drop across the salt bed, which is related to mass transfer) and one local variable (salt bed temperature). Experimental results from two types of open thermochemical storage system were available at the PROMES laboratory for this purpose:

- A mass transfer characterization bench, using reactive beds with a wide range of densities (bed energy density $300-600 \mathrm{kWh} \cdot \mathrm{m}^{-3}$ ).

- A large-scale prototype of seasonal thermochemical storage (400 kg of salt), run experimentally in different operating conditions. 
These experimental set-ups have already been described elsewhere [5, 18], and so are presented only briefly here $(\S 3)$.

This work thus uses experimental results from two different experimental devices to make a fine analysis of the local behavior of thermochemical solid-gas reactors.

\section{Thermochemical process}

An open seasonal thermochemical storage system for house heating, containing a packed bed of reactive salt, works as follows:

- During the heating period (winter): moist air flow through the reactor, causing the exothermic hydration of the dehydrated salt $\mathrm{S}_{0}\left(\mathrm{SrBr}_{2} \cdot 1 \mathrm{H}_{2} \mathrm{O}\right)$ to $\mathrm{S}_{1}\left(\mathrm{SrBr}_{2} \cdot 6 \mathrm{H}_{2} \mathrm{O}\right)$. The heat of reaction $\left(5 \Delta h_{r}^{0}\right.$ per mole of salt) warms the moist air flow, which acts as a heat transfer fluid. This fluid flow then exchanges heat with the air inside the house. At the end of this period, the salt bed is fully hydrated $\left(\mathrm{SrBr}_{2} \cdot 6 \mathrm{H}_{2} \mathrm{O}\right)$.

- During the storage period (summer): moist air is heated by solar collectors. This hot air then flows through the porous bed of $\mathrm{S}_{1}\left(\mathrm{SrBr}_{2} \cdot 6 \mathrm{H}_{2} \mathrm{O}\right)$. This causes an endothermic dehydration of salt $S_{1}$ to $S_{0}$.

- Between the storage and heating periods, the reactor is sealed from gas flow. During this interval the heat is stored as a chemical potential, so there are no heat losses through cooling. Thermochemical storage is thus particularly well-suited to long-term heat storage such as seasonal storage.

We note that a thermochemical storage system requires a high-density salt bed, and an open working mode requires large flows of non-reactive gas. Mass transfer is thus usually the main limitation of the reaction [37], and so the reactive bed has to be carefully designed.

\section{Experimental devices and protocols}

\subsection{Characterization bench}

This experiment was carried out to characterize the mass transfer (permeability) and the reaction kinetics of reactive porous beds for different implementation variables (energy density, bed thickness, etc.).

The operating principle of the experimental bench (fig. 1) is based on the measurement of the pressure drop, $\Delta p$, across the porous packed bed, and the flowrate, $\dot{V}$, of moist air (at controlled humidity and temperature) passing through it. From this we deduce $\mathrm{k}_{e q}$, the equivalent permeability of the packed bed according to Darcy's law. Assuming a unidirectional flow, in a steady state, and $\Delta p \ll \mathrm{p}_{a m b}$, the permeability $\mathrm{k}_{e q}\left(m^{2}\right)$ is defined by the following equation:

$$
k_{e q}=\frac{\mu Z_{s} \dot{V}}{|\Delta p| \Omega}
$$

with $\Omega$ the cross section of the bed $\left(\mathrm{m}^{2}\right)$, and $\mathrm{Z}_{s}$ the bed thickness $(\mathrm{m})$. 

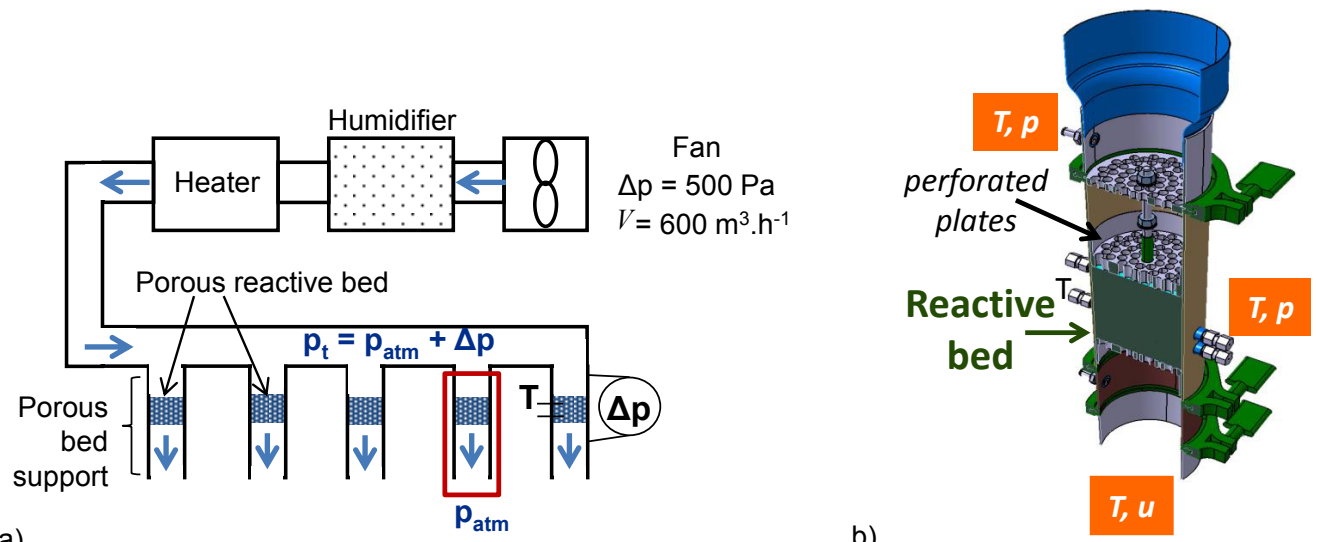

a)

b)

Figure 1: Experimental set-up for mass transfer and kinetics measurements. a) experimental bench with several sample holders. b) sample holder (adapted from [18]).

The salt bed was confined between two perforated metal plates that fixed its density at a set value. The bed thickness ranged from 40 to $100 \mathrm{~mm}$, in a $100 \mathrm{~mm}$ diameter tube. The vapor pressures at the bed inlet and outlet and the bed temperature were measured. The experimental bench included a fan, a humidifier, and an electric heater (fig. 1) ), which were controlled to regulate the pressure, temperature and humidity of the airflow at the sample inlet. The kinetics and the reaction advancement were deduced from the weight variation of the sample. Permeabilities could thus be measured at different advancement of the reaction $\mathrm{X}_{g}$.

The advancement of the reaction was calculated from the sample mass measurement $\left(\mathrm{m}_{s X}\right)$ :

$$
X_{g}=\frac{m_{s X}-m_{s 0}}{m_{s 1}-m_{s 0}}
$$

where $\mathrm{m}_{s 0}$ and $\mathrm{m}_{s 1}$ are the masses of the dehydrated and hydrated salt bed, respectively. $\mathrm{m}_{s 0}$ was measured at the start of hydration and $\mathrm{m}_{s 1}$ results from the rule of mass additivity:

$$
m_{s 1}=\frac{m_{s 0}}{M_{s 0}}\left(\nu M_{v}+M_{s 0}\right)
$$

Several samples, with different implementation variables (density, bed thickness, etc.) and operating conditions (inlet air temperature and humidity) were tested and characterized. For these experiments, the pressure drop across the sample was fixed $(\Delta p=500 \mathrm{~Pa})$. The other operating conditions are listed in table 1.

\subsection{Large scale prototype of a thermochemical storage reactor}

The second available experimental device was a large scale thermochemical reactor prototype. It was designed and sized to achieve a high energy density and a specific power suitable for space heating of residential housing (specific power at the reactor output $0.3-0.8 \mathrm{~W} \cdot \mathrm{kg}^{-1}[5,40]$ ). The reactor was of modular design, stacking eight rectangular modules fed in parallel (fig. 2). Both 


\begin{tabular}{|c|c|c|c|c|c|}
\hline \multicolumn{2}{|c|}{ Operating conditions of different samples } & $\begin{array}{l}\mathrm{p}_{v i}(\mathrm{~Pa}) / \mathrm{HR}(\%) \\
/ \mathrm{w}\left(\mathrm{g}_{v} / \mathrm{kg}_{a}\right)\end{array}$ & $\begin{array}{l}T_{v i} \\
\left({ }^{\circ} \mathrm{C}\right)\end{array}$ & $\begin{array}{l}Z_{s} \\
(\mathrm{~cm}) \\
\end{array}$ & $\operatorname{Dec}\left(k W h \cdot m^{-3}\right)$ \\
\hline \multirow{7}{*}{ Sample 1: } & $1^{\text {st }}$ hydration & $1395 / 47 / 8.7$ & 23.9 & \multirow{7}{*}{4.84} & \multirow{7}{*}{433.5} \\
\hline & $2^{\text {nd }}$ hydration & $1464 / 63 / 9.1$ & 19.9 & & \\
\hline & $3^{\text {rd }}$ hydration & $1322 / 55.5 / 8.2$ & 20.3 & & \\
\hline & $4^{t h}$ hydration & $1181 / 54.1 / 7.3$ & 18.9 & & \\
\hline & $5^{t h}$ hydration & $1353 / 69 / 8.4$ & 17.2 & & \\
\hline & $6^{\text {th }}$ hydration & $982 / 58 / 6.1$ & 14.9 & & \\
\hline & $7^{\text {th }}$ hydration & $998 / 50 / 6.2$ & 17.5 & & \\
\hline \multirow{2}{*}{ Sample 2: } & $1^{\text {st }}$ hydration & $1277 / 22.7 / 7.9$ & 35 & \multirow{2}{*}{7.5} & \multirow{2}{*}{400.78} \\
\hline & $1^{s t}$ dehydration & $1497 / 8.8 / 9.3$ & 56.6 & & \\
\hline
\end{tabular}

Table 1: Operating conditions and characteristics of the reactive salt beds tested with the characterization bench (adapted from [18]).

\begin{tabular}{|c|c|}
\hline & Prototype \\
\hline Reactor dimensions*, h x L x l (cm) & $99.3 \times 77.5 \times 72$ \\
\hline Reactor external dimensions, h x L x l (cm) & $130 \times 106 \times 90$ \\
\hline Module dimensions, h' x L' x l' (cm) & $8 \times 69.4 \times 65.1$ \\
\hline Air collector dimensions, $\mathrm{h} \times \mathrm{L} \times \mathrm{l}(\mathrm{cm})$ & $99.3 \times 3 \times 72$ \\
\hline Mass diffuser dimensions, $\mathrm{h} \times \mathrm{L} \times \mathrm{l}(\mathrm{cm})$ & $1.5 \times 69.4 \times 65.1$ \\
\hline Bed thickness, $\mathrm{Z}_{s}(\mathrm{~cm})$ & 7.5 \\
\hline Mass of hydrated salt, $\mathrm{m}_{s 1}(\mathrm{~kg})$ & 400 \\
\hline Salt bed energy density, Dec $\left(\mathrm{kWh} \cdot \mathrm{m}^{-3}\right)$ & 388 \\
\hline Reactor energy density*, Der $\left(\mathrm{kWh} \cdot \mathrm{m}^{-3}\right)$ & $203^{*}$ \\
\hline
\end{tabular}

Table 2: Geometric characteristics of the prototype. (* excluding feet, insulation and ninth module) (adapted from $[5])$

the top and bottom of each module came into contact with moist air flow from a $1.5 \mathrm{~cm}$ wide air duct. These air ducts were connected to the reactor air inlet collector and supplied moist air to the reactive salt. This air flowed axially through the reactive bed, and was collected on the opposite side via an outlet air collector (fig. 2).

The reactor prototype dimensions and characteristics are summarized in table 2. It contained $400 \mathrm{~kg}$ of hydrated salt and could store $105 \mathrm{kWh}$ of heat. The packed bed energy density was 388 $\mathrm{kWh} \cdot \mathrm{m}^{-3}$ and the reactor energy density was $203 \mathrm{kWh} \cdot \mathrm{m}^{-3}$. The reactor was connected to an aeraulic test bench that allowed control of the inlet moist air flow conditions (temperature, moisture, flow rate).

Several sensors were used to evaluate prototype performance and thermochemical reaction progress. The moist air conditions (flow rate $( \pm 0.8 \%)$, relative humidity $( \pm 0.8 \%)$ and temperature (PT100: $\left.\pm 0.2^{\circ} \mathrm{C}\right)$ ) and the total pressure difference $( \pm 10 \mathrm{~Pa})$ were measured at the inlet and outlet pipes of the reactor. Inside the reactor, eight thermocouples were distributed in the 


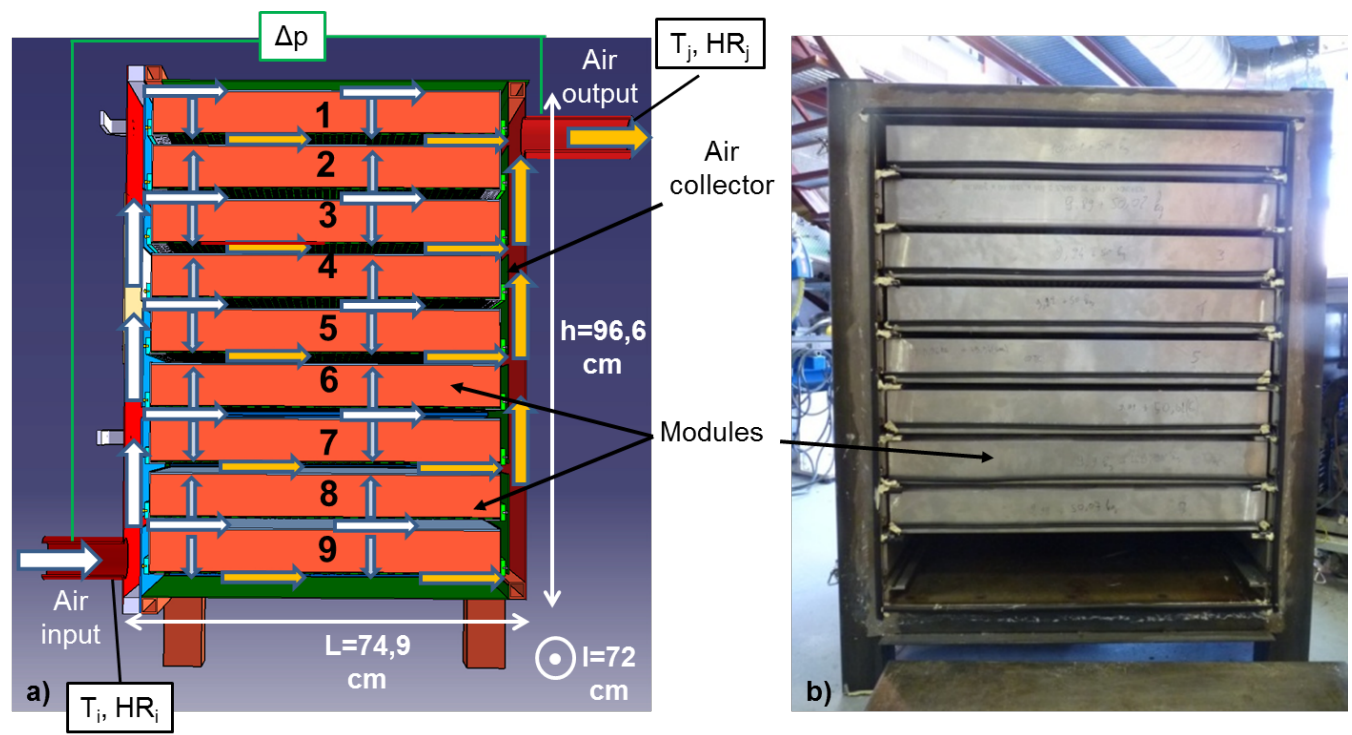

Figure 2: Reactor prototype. a) Vertical section, including air flow paths. b) Photograph of the open prototype. Dimensions are in table 2 (adapted from [5]).

salt bed bulk of modules 4 and 5 (uncertainties $= \pm 0.3{ }^{\circ} \mathrm{C}$ ). The reactor was weighed continuously to measure reaction advancement as defined by Equation 5. From these measurements, and using correlations based on Standard NFX15-110 and Ashrae Handbook Fundamentals [41], we could calculate all the characteristics of the moist air flow (temperature, humidity, enthalpy, density, etc.). The equivalent permeability of the eight reactive beds could also be calculated using Eq.(4). For this experiment, the flowrate, $\dot{\mathrm{V}}$ and the $\Delta \mathrm{p}$ are respectively the inlet flowrate of the reactor and the total pressure difference in the reactor. Measurements are recorded every $30 \mathrm{~s}$ and the presented results are averaged values over $30 \mathrm{~min}$ of recorded data.

The thermochemical storage prototype was tested over a period of five months. As the study focused on a seasonal storage system, the cycle times were rather long (15-20 days), and only seven hydration/ dehydration cycles were performed. Also, cycles did not go to completion $\left(\Delta X_{g}<1\right)$ because rate decreased considerably at the very end of the reaction, and so reaction completion would have taken too long. The experiments analyzed here were performed at similar constant mass flow rate and moist air conditions (moisture, temperature). The average operating conditions are summarized in table 3 .

\section{Experimental results: reactive bed changes during reactions}

This section analyzes the local changes in a reactive bed of an open thermochemical storage system. Overall performance and the ways to control the system were studied in previous work [5]. The two experimental devices described above allow the study of reactive beds at different scales, with different bed implementations, and during dehydration/hydration reactions. This study focuses on the state variables that are experimentally available: two overall variables, reaction advancement and pressure drop across the salt bed, allow an analysis of reaction stability and mass 


\begin{tabular}{|l|l|l|l|l|}
\hline & $\mathrm{T}_{i}\left({ }^{\circ} \mathrm{C}\right)$ & $\begin{array}{l}\mathrm{p}_{v i}(\mathrm{~Pa}) / \mathrm{HR}(\%) \\
/ \mathrm{w}\left(\mathrm{g}_{v} / \mathrm{kg}_{a}\right)\end{array}$ & $\begin{array}{l}\text { Air flow rate } \\
\left(\mathrm{m}^{3} / \mathrm{h}\right)\end{array}$ & $\begin{array}{l}\text { Overall advancement } \\
\mathrm{X}_{g} \text { initial } / \text { final }\end{array}$ \\
\hline Dehydrations & 80 & $2557 / 5.4 / 16.1$ & 312.6 & $1 / 0$ \\
\hline $1^{\text {st }}$ & 77.9 & $2570 / 5.9 / 16.2$ & 311.2 & $0.57 / 0.2$ \\
\hline $2^{\text {nd }}$ & 79.8 & $2459 / 5.2 / 15.5$ & 313 & $0.83 / 0.35$ \\
\hline $3^{\text {rd }}$ & 79.8 & $2468.7 / 5.2 / 15.5$ & 312.9 & $0.55 / 0.28$ \\
\hline $6^{\text {th }}$ & \multicolumn{5}{|l|}{} \\
\hline Hydrations & $997.5 / 31.5 / 6.2$ & 289.6 & $0 / 0.58$ \\
\hline $1^{\text {st }}$ & $981 / 31 / 6.1$ & 290 & $0.05 / 0.82$ \\
\hline $2^{\text {nd }}$ & 25 & $944.7 / 29.8 / 5.6$ & 290 & $0.14 / 0.82$ \\
\hline $3^{\text {rd }}$ & 25 & $982.2 / 31.2 / 6.1$ & 290 & $0 / 0.8$ \\
\hline $4^{\text {th }}$ & 25 & $980.4 / 31.1 / 6.1$ & 284.4 & $0.28 / 0.7$ \\
\hline $6^{\text {th }}$ & 24.9 & 24.9 & 271.8 & $0.55 / 0.89$ \\
\hline $7^{t h}$ & 24.8 & $968.2 / 31 / 6$ & \pm 4 & - \\
\hline Maximal deviation & \pm 0.2 & $\pm 50 /-/ \pm 0.3$ & \pm 4 \\
\hline
\end{tabular}

Table 3: Operating conditions of each reaction carried out at a constant mass flow rate and equilibrium drop (reactor prototype) (adapted from [5]).

transfer (Darcy's law, Eq. 4, links pressure gradient and bed permeability) and their changes within the bed and over successive reactions; the salt bed temperature analysis yields information on reaction advancement inside the bed.

\subsection{Analysis of overall state variables: reaction advancement and pressure drop across the salt bed}

\subsubsection{Reaction stability}

Reaction stability during successive cycles is a recurrent issue in solid/gas thermochemical systems [21, 42]. Reaction reversibility and cycling have been verified for several thermochemical systems using ammoniates. For the reactive hydrate pair studied $\left(\mathrm{SrBr}_{2} / \mathrm{H}_{2} \mathrm{O}\right)$, this question was addressed on the two experimental benches described in $\S 3$.

fig. 3(a) and (b) presents the time course of the hydration reaction for seven successive cycles, measured respectively by the characterization bench (Sample 1, §3.1) and the thermochemical storage prototype. First, we note that in both cases the reaction rate was not constant, but decreased as the reaction progressed. This effect is well-known for such solid/gas reactions.

The results for reaction times displayed some dispersion, which can be analyzed and explained. On the characterization bench (fig. 3(a)), excluding the first hydration (at higher inlet air temperature), the hydrations can be roughly split into two groups: the first group includes hydrations 2, 3 and 5, and the second group hydrations 4,6 and 7. The reaction rates were slower for Group 2 because of different operating conditions, and in particular lower partial pressure of water of the air inlet (respectively about $1300 \mathrm{~Pa}$ and $990 \mathrm{~Pa}$ for Groups 1 and 2), which leads to a lower equilibrium drop. This equilibrium drop, defined as the difference between moist air conditions and thermodynamic equilibrium of the reaction stated by Eq. 2, has a marked impact on the reaction time [24]. Hence no significant changes in the reaction kinetics were observed during the seven hydrations. 

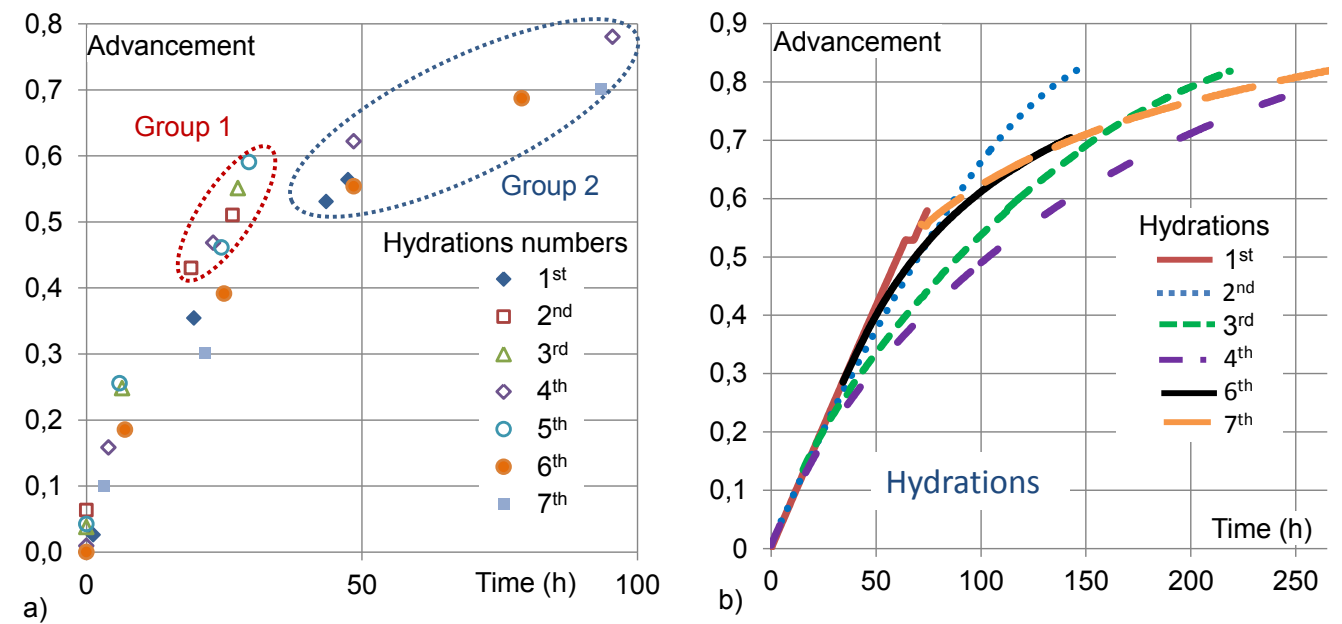

Figure 3: Progress point vs. time for 7 hydrations: a) from characterization bench (Sample 1, see §3.1); b) from reactor prototype. Reactions are uncompleted and begin at different advancements (see §3.2) (adapted from [5, 18]).

In the prototype experiment (fig. 3(b)), reaction time increased over the first four cycles. Reaction time at mid-reaction $\left(\mathrm{X}_{g}=0.5\right)$ was 1.7 times longer from the first to the fourth hydration. However, the reaction rate seemed to stabilize from the sixth cycle. This rate diminution for the very first cycles followed by stabilization after a few cycles has already been underlined for such solid/gas reactions [43]. It can be explained by a change in the texture of the porous bed due to the mechanical stress resulting from the variation in salt grain volume from the dehydrated to the hydrated state.

These two experiments at very different scales thus gave consistent results, confirming acceptable reaction stability. Further experiments are in progress to measure the kinetics over a long period of time cycling at the prototype scale.

\subsubsection{Bed equivalent permeability}

In an open thermochemical storage system, mass transfer through the porous bed is usually the main limit to the reactive bed transformation, and it has a marked influence on system performance (the power supply is directly related to the mass air flowrate, as detailed in the overall performance analysis [5, 37]). In such porous beds, mass transfer is considered through the bed permeability, which is, according to Darcy's law (eq. 4), proportional to the pressure drop at the bed boundaries: $\mathrm{k} \sim 1 / \Delta \mathrm{p}$.

Knowing the order of magnitude and variation of the permeability is a key point when designing such a system. This permeability depends on the implementation of the porous bed represented by parameters such as bed density, porosity, tortuosity, grain size, etc. Among them, bed density is a key parameter because it is trade-off between two antagonistic requirements: a high bed density offers a high energy density required for a thermal storage system, but it also reduces bed porosity, and so can slow gas transfer. On the other hand, the reaction itself changes the bed porosity and can have an impact on its permeability.

The next section presents experimental studies of bed permeabilities performed on both experimental beds, and their time course, according to the two main variables: bed density and reaction 
advancement.

a) Influence of the energy density.

Using the characterization bench, several beds with different implementation variables (density, porosity, grain size) were experimented (§3.1).

fig. 4 summarizes the bed permeabilities according to their density expressed as energy densities (Dec, $\mathrm{J}$ or $\mathrm{kWh}$ of energy stored $/ \mathrm{m}^{3}$ of porous bed). This variable was investigated in the range targeted for long-term storage applications $\left(300-600 \mathrm{kWh} \cdot \mathrm{m}^{-3}\right)$. Permeabilities were measured at the boundaries of the reaction: $\mathrm{k}_{0}$ for the dehydrated salt bed, $\operatorname{SrBr}_{2} \cdot 1 \mathrm{H}_{2} \mathrm{O}$, and $\mathrm{k}_{1}$ for the hydrated salt bed, $\mathrm{SrBr}_{2} \cdot 6 \mathrm{H}_{2} \mathrm{O}$, i.e. at $\mathrm{X}_{g}=1$.
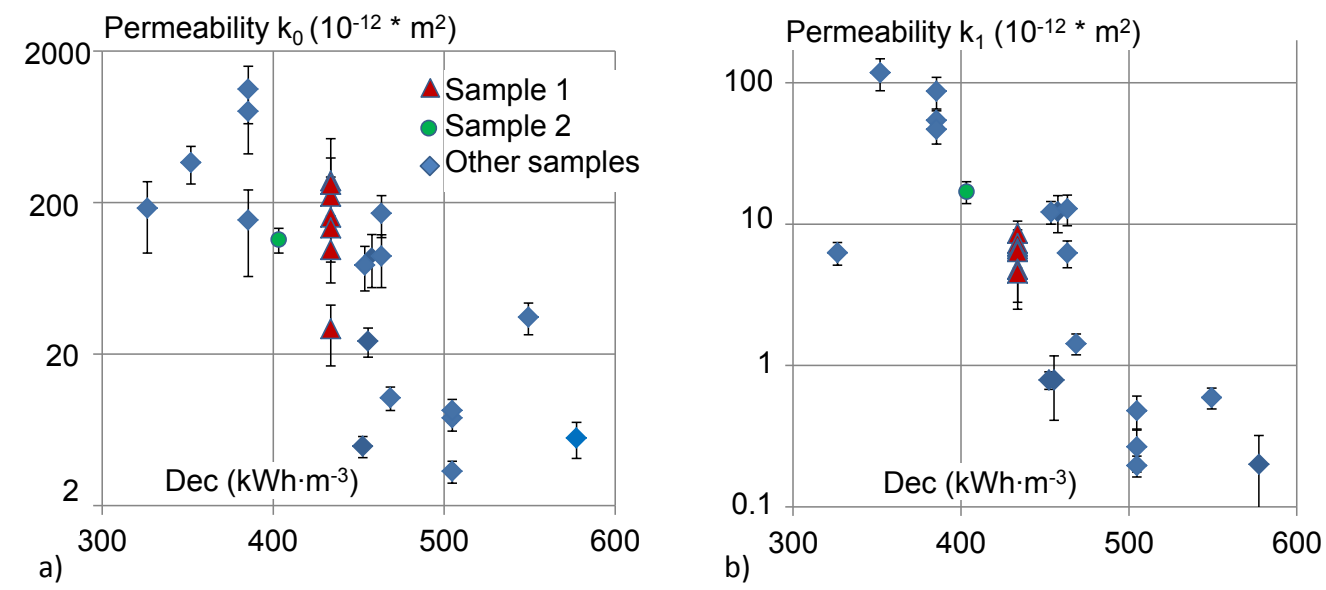

Figure 4: Permeability vs energy density of thermochemical porous beds (see bed characteristics table 1) a) $\mathrm{k}_{0}$, for the dehydrated bed i.e. at the overall reaction advancement $\mathrm{X}_{g}=0 ; \mathrm{b}$ ) $\mathrm{k}_{1}$, for the hydrated bed at $\mathrm{X}_{g}=1$.

These figures showed a strong decrease in permeability vs. energy storage density and bed density. The permeability changed by three orders of magnitude when the energy density ranged from 300 to $600 \mathrm{kWh} \cdot \mathrm{m}^{-3}$. Thus bed density has a very strong effect on mass transfer, and so the reactive bed has to be carefully implemented to control the mass transfer limitation. In addition, the permeability changed strongly during the reaction, decreasing by more than one order of magnitude. This is due to the difference in salt grain volume between the dehydrated and hydrated states.

A marked change in permeability in the course of the reaction can have a significant impact on reactor performance. Accordingly, the way these two boundaries changed was investigated more thoroughly, as described in the following section.

b) Influence of the overall reaction advancement.

The small scale characterization bench and the prototype both enabled us to study the time course of permeability as the reaction progressed. For the small bench, fig. 5(a) and (b) show the bed permeabilities as a function of the overall reaction advancement for seven hydrations of Sample 1 and one cycle (hydration/dehydration) of Sample 2. 
fig. 5(c) and (d) present a similar experimental study for the reactive bed implemented in the prototype, for several hydrations (fig. 5(c)) and dehydrations (fig. 5(d)), run at similar airflow conditions (see table 3).
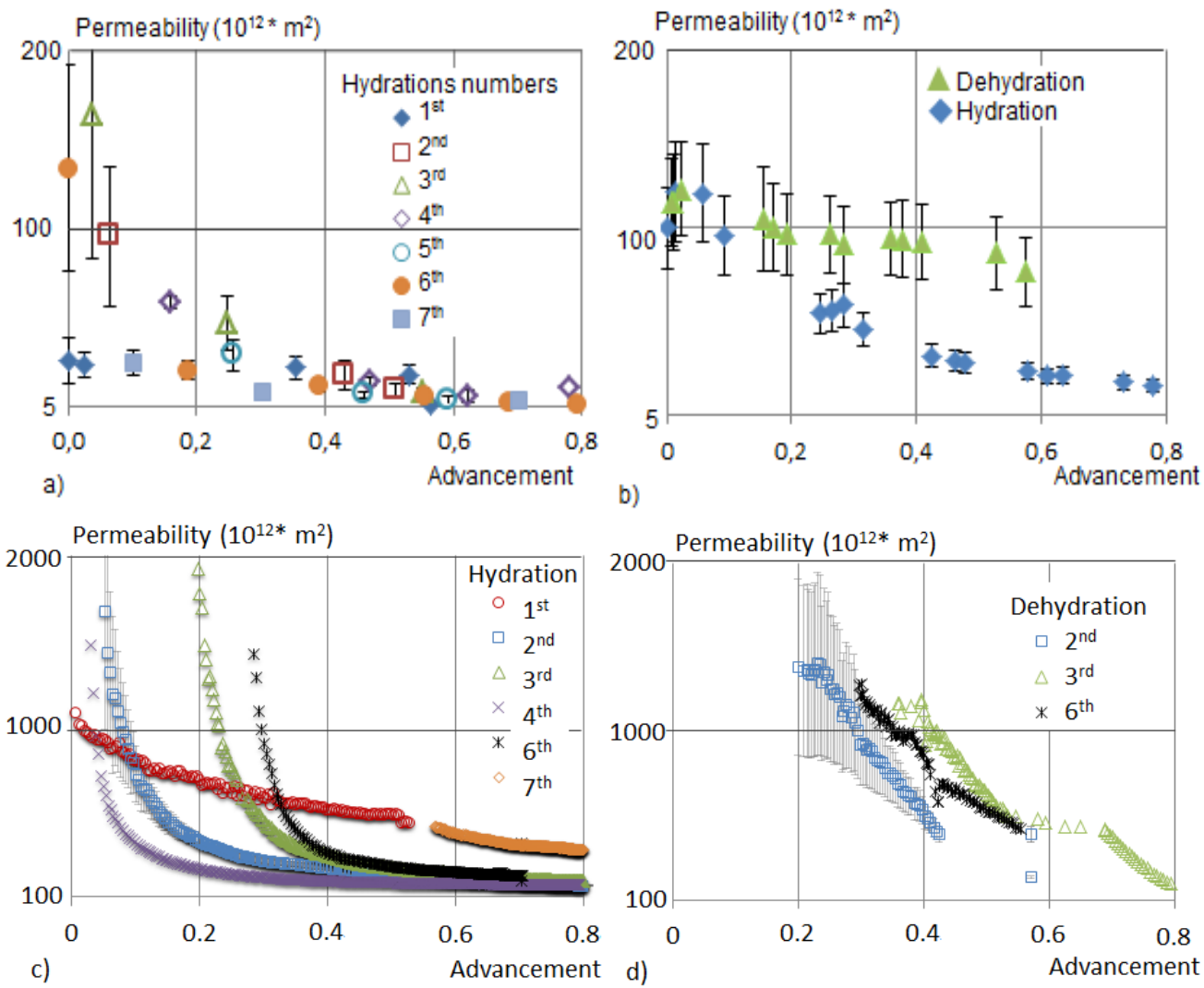

Figure 5: Time course of the permeability of a reactive bed as a function of the overall advancement: a) for seven successive hydrations of Sample $\left.1\left(\operatorname{Dec}=433.5 \mathrm{kWh} \cdot \mathrm{m}^{-3}\right) ; \mathrm{b}\right)$ for a dehydration/hydration cycle of Sample $2($ Dec $=$ $\left.400.8 \mathrm{kWh} \cdot \mathrm{m}^{-3}\right)$ - Characterization bench; c) during hydrations; d) during dehydrations - prototype reactor (Dec $=$ $388 \mathrm{kWh} \cdot \mathrm{m}^{-3}$ ). The uncertainities of the permeability are represented for the second cycle. They are representative of the uncertainities of the other cycles. (Note that reactions did not go to completion owing to experimental difficulties; the reaction advancement range is therefore different for each reaction).

Permeability measurements are arduous because of the difficulties of accurately and reproducibly measuring a pressure drop in an airflow at the boundaries of a porous material. Despite discrepant measurements, these figures highlight some interesting tendencies.

The characterization bench results for Sample 1 (fig. 5(a)) show that the permeabilities changed during the reaction between the boundaries as plotted on fig. 4(a) and (b). They are in the range $10^{-10}-10^{-12} \mathrm{~m}^{2}$. These measurements were largely reproducible after the second cycle, demonstrating the stability of the bed texture. The most important point is the shape of the time course: the permeability does not decrease linearly, but following a $1 / \mathrm{X}_{g}$ function. 
Sample 2 presented slightly higher permeabilities (fig. 5(b)) than Sample 1 owing to the lower density of this bed (see caption). For the hydration, both samples presented similar non-linear shapes for the permeability time course. However, during the dehydration reaction, the permeability time course measured was different and could be linearized.

For the prototype reactor, the permeability time course plots are presented in fig. 5(c) and fig. 5(d) respectively for hydrations and dehydrations. In both cases, fig. 5 shows that for a given degree of advancement, the equivalent permeability of the reactive bed changed during the first cycles owing to a change in the porous bed texture, as explained previously. Nevertheless, this permeability change was small compared with its time course over the whole reaction: it decreased/increased by more than one order of magnitude $\left(10^{-9}\right.$ to $\left.10^{-10} \mathrm{~m}^{2}\right)$ during hydration/dehydration. The permeability of the dehydrated bed was about $\mathrm{k}_{0} \sim 10^{-9} \mathrm{~m}^{-2}$ (estimated by extrapolation at $\mathrm{X}_{g}=0$ from fig. 5(c)), and it was consistent with the characterization bench results for the density of the prototype bed $\left(388 \mathrm{kWh} \cdot \mathrm{m}^{-3}\right)$. fig. 5 further shows that in the case of hydration, the bed permeability time course was characterized by a strong decrease at the beginning followed by a weaker decrease towards the end of the reaction. In dehydration, the permeability changed largely linearly throughout the reaction. Hence the two experiments show similar tendencies: the reactive bed permeability changed as $\mathrm{f}\left(1 / \mathrm{X}_{g}\right)$ in hydration and as $\mathrm{f}\left(\mathrm{X}_{g}\right)$ in dehydration.

An intuitive explanation is attempted for these time course patterns. The experiment measures an equivalent permeability of the bed, at the overall reaction advancement $\mathrm{X}_{g}$. However, in hydration, we can assume that a reaction front in the reactive bed [37], separates two layers in it: a fully hydrated layer $(X=1)$ and a dehydrated layer $(X=0)$. This reaction front moves in the same direction as the air flow, i.e. from the air inlet to the other side of the reactive bed (see fig. 6(a)). At the overall advancement, $\mathrm{X}_{g}$, the thicknesses of the two layers are respectively $\mathrm{X}_{g} \cdot \mathrm{Z}_{s}$ and $\left(1-\mathrm{X}_{g}\right) \cdot \mathrm{Z}_{s}$, and their permeabilities are respectively $\mathrm{k}_{1}$ and $\mathrm{k}_{0}$. Thus the equivalent permeability of the bed can be expressed as a serie combination of these two layers:

$$
k_{e q}\left(X_{g}\right)=\frac{1}{\frac{X_{g}}{k_{1}}+\frac{1-X_{g}}{k_{0}}}
$$

In this case, the permeability $\mathrm{k}_{e q}$ thus depends on $\left(1 / \mathrm{X}_{g}\right)$. Conversely, during the dehydration step, the experiment shows that the permeability changed linearly (fig. 5(b) and (d)). Such a linear time course could occur if the reactive bed is made of fully hydrated and dehydrated parts operating in parallel. This reactive layer configuration could be explained by diffusion paths through the reactive bed created by the dehydration. fig. 6(b) schematizes an example of this case. The equivalent permeability of the bed is expressed as the following linear function:

$$
k_{e q}\left(X_{g}\right)=k_{0} X_{g}+k_{1}\left(1-X_{g}\right)
$$

To conclude, despite some discrepancies in permeability values due to difficulties in accurately measuring gas flowrates through a porous bed, especially for high permeabilities, the two experiments gave consistent results, highlighting a marked change in reactive bed permeability during the reaction. This permeability change strongly impacts the mass transfer in the reactive bed, and so knowledge of it could help in designing and modeling thermochemical storage systems.

The bed permeability changed by up to two orders of magnitude between the hydrated and dehydrated states, and between these two states, we observe an asymmetric permeability time course. 


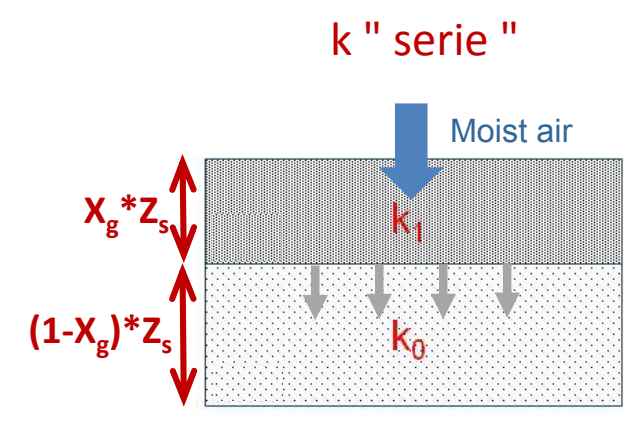

a)

Figure 6: Permeability time course during the reactions. a) Series combination of fully reacted and unreacted layers (assumption for hydration). b) Example of a parallel combination of two fully reacted areas and one unreacted area (assumption for dehydration step). Small white or grey arrows represent the movement of the reaction front.

This may be explained by a series combination of hydrated and dehydrated layers during hydration, and a parallel combination of these layers during dehydration. However, because of the lack of local data and technical means to measure local reaction advancement, this interpretation could not be validated. To complete the study of reactive bed behavior, a local analysis of the bed temperature was carried out and is presented below.

\subsection{Analysis of the local bed temperature}

The reactive bed local temperatures were studied in the prototype modules 4 and 5 (fig. 2, §3.2) and for different reactions. These modules were located at mid-height of the prototype and so were less strongly affected by boundary effects than the other modules. Also, they were finely monitored, each module having four thermocouples located at different heights in the bed bulk to measure the local temperature time course during the reaction. A schematic diagram showing the thermocouple locations is presented in fig. 7 .

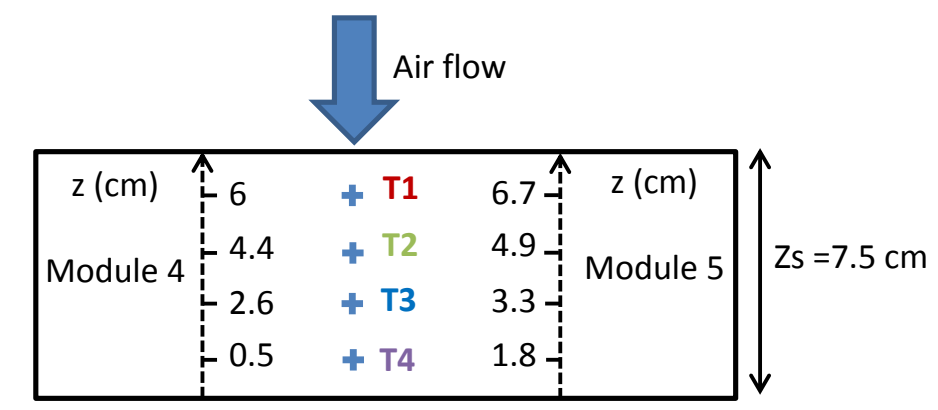

Figure 7: Diagram of modules 4 and 5 and location of thermocouples T1 (near the top of the salt layer, and the air inlet) to T4 (near the bottom of the salt layer, and the air outlet). 


\subsubsection{Reaction front location}

fig. 8(a) presents the local temperatures (T1-T4) of modules 4 and 5 and the reactor outlet air temperature, as a function of reaction advancement, for the first dehydration. We observe that on injecting a moist air flow at $80^{\circ} \mathrm{C}$ (cf. table 3), all the salt temperatures (T1 to $\mathrm{T} 4$ ) of both modules increased and reached a plateau at about $61^{\circ} \mathrm{C}$, before increasing again, each thermocouple in turn, to reach a temperature close to the reactor inlet air temperature. Thus at the overall advancement $\mathrm{X}_{g}=0$ (end of this dehydration reaction) all thermocouples tended towards the inlet air flow temperature $\left(80^{\circ} \mathrm{C}\right)$.

This salt bed temperature time course indicates that a reaction front moved from the top (T1) towards the bottom of the salt bed (T4), i.e. from the inlet of moist air towards its outlet. On the reaction front, the endothermic dehydration reaction consumes the sensible heat of the moist air flow. Thus the moist air temperature reaches the equilibrium temperature of the thermochemical reaction $[5,34]$. Downstream of the reaction front, the moist air flow then brings the unreacted salt layer close to the equilibrium temperature.

When the endothermic reaction is completed in a part of the salt layer (upstream of the reaction front), the salt bed temperature gradually increases to reach the inlet moist air temperature.

We note that because the moist air flow permeates the whole reactive bed, and imposes its temperature downstream of the reaction front, it is impossible to determine the start of the reaction at any specific point in the bed. We can only observe that the reaction is almost completed at a given point in the bed when its temperature tends toward the inlet moist air temperature.

Also, we note that at the advancement $\mathrm{X}_{g}=0.08$, a breakdown of the aeraulic bench test occurred. Dry air was injected into the reactor, and a modification of the reaction equilibrium temperature ensued, causing a sudden drop in the salt bed temperature. Thus the reactor temperature is very sensitive to inlet moist air conditions, and its response to any change in the inlet air conditions is very fast. A thorough analysis of the influence of inlet air conditions on the reaction kinetics was presented in a previous paper [5].

Finally, this local temperature analysis demonstrates that in dehydration, the permeability linear time course cannot be explained by the simple assumption of fully hydrated and dehydrated parts operating in parallel (§4.1.2b, fig. $7(\mathrm{~b}))$. The reactive layer configuration is certainly more complex, with a reaction front moving along the air flow axis and possible diffusion paths through the reactive bed created by the dehydration.

Similar results were observed during hydration 1, and are presented in fig. 8(b). This hydration reaction is uncompleted (stopped at $\mathrm{X}_{g}=0.55$ due to failure in the steam generation device): only salt temperatures $\mathrm{T} 1$ and $\mathrm{T} 2$ went from the plateau temperature (reaction equilibrium temperature around $\left.33.5^{\circ} \mathrm{C}\right)$ to the inlet moist air temperature $\left(25^{\circ} \mathrm{C}\right)$. Hence the reaction was completed in the salt layer up to $\mathrm{T} 2$, but was still uncompleted at the T3 and $\mathrm{T} 4$ locations.

fig. 8(a) and (b) also show that the outlet air temperature differed slightly from the plateau temperature: a few degrees higher in dehydration, and lower in hydration. An explanation may be that part of the moist air flow injected in the reactor does not go through the reactive layer, because of leakage between the reactor walls and the modules or preferential paths through the salt bed. 

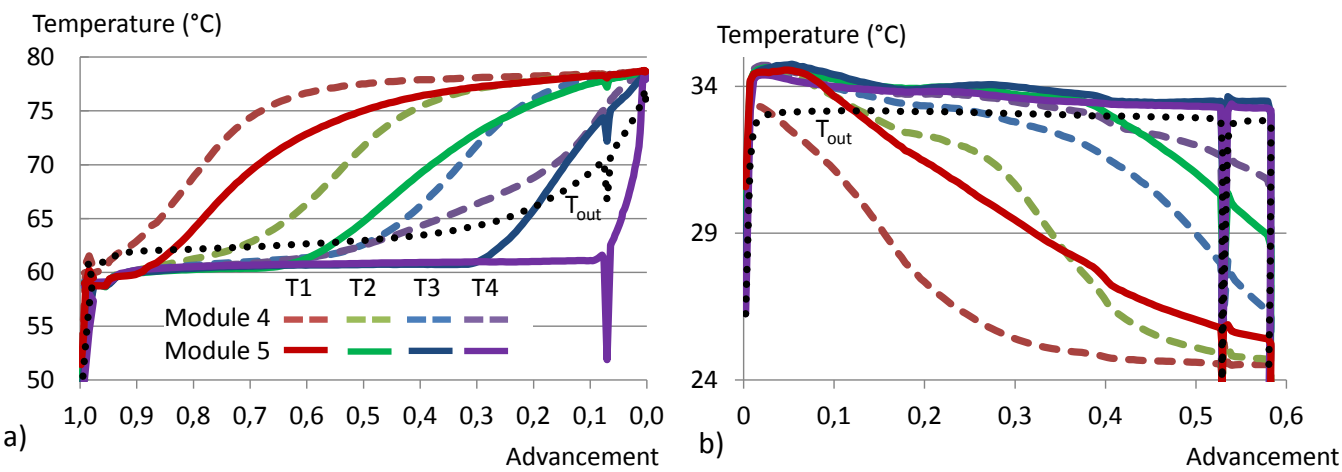

Figure 8: Salt bed temperatures of the prototype modules 4 and 5 (T1 to T4) and air outlet temperature $\left(\mathrm{T}_{\text {out }}\right)$ : a) during the first dehydration; b) during the first hydration.

\subsubsection{Change of the reaction front location}

In this section, the thermal time course of the reactive bed in module 5 is analyzed for several successive hydration reactions.

fig. 9 shows the temperature T1-T4 and the overall reaction advancement as a function of time, for
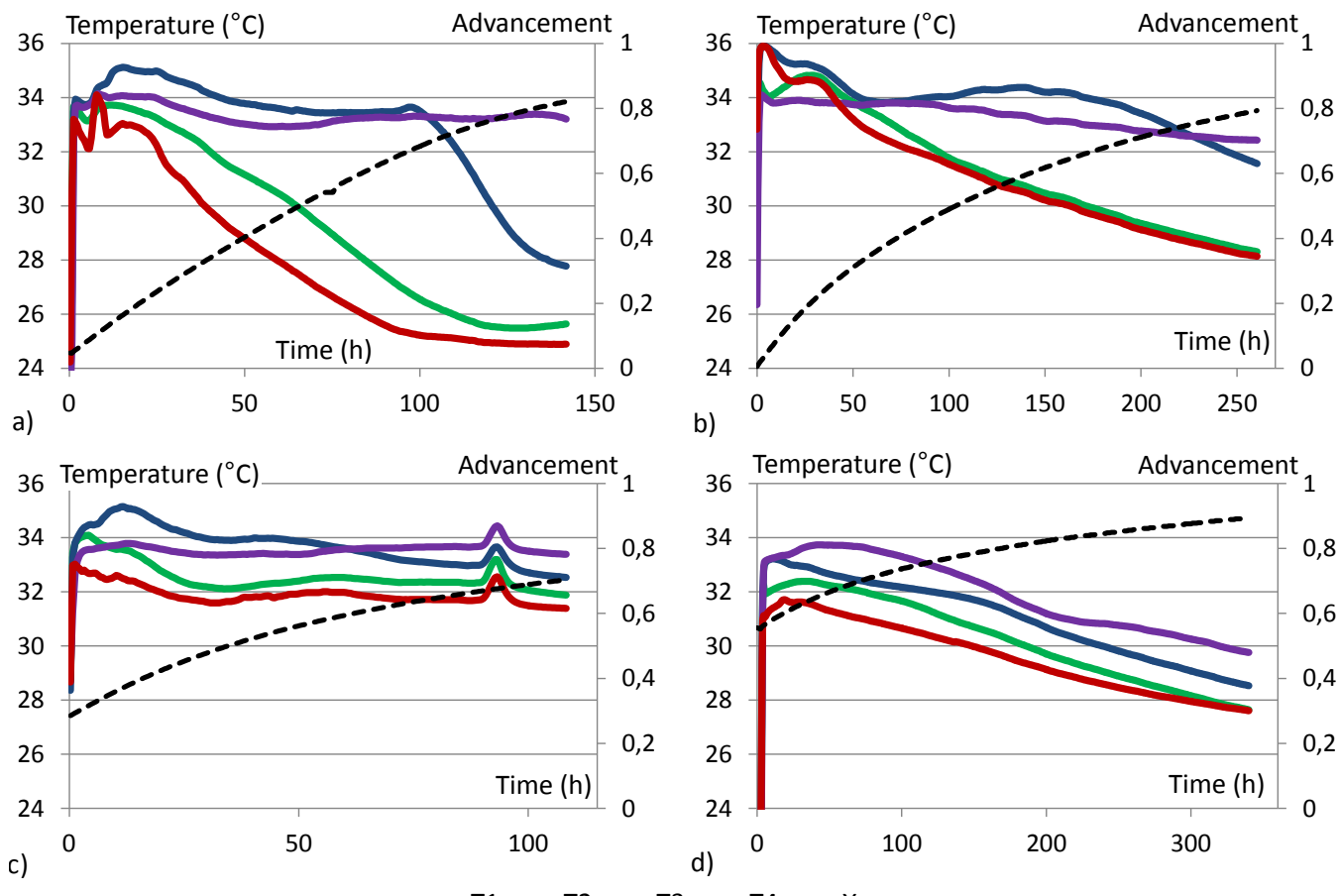

b)

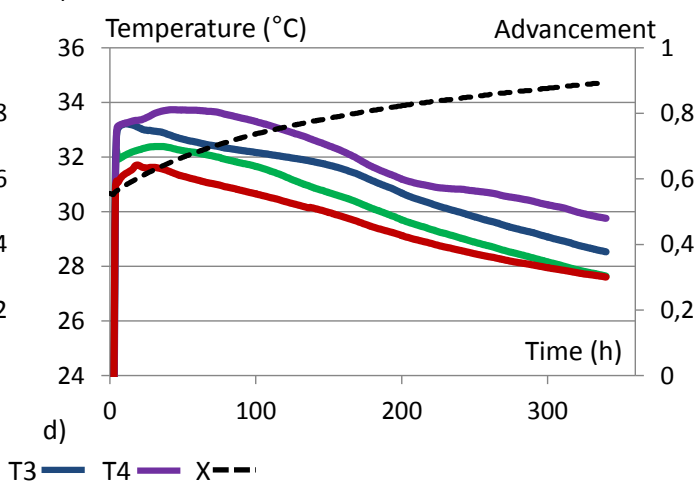

Figure 9: Local temperatures of the prototype module 5 (T1-T4) and reactor overall advancement, as a function of time, for: a) the hydration 2 ; b) the hydration 4 ; c) the hydration 6 and; d) the hydration 7 . 
hydration 2 (fig. 9(a)), hydration 4 (fig. 9(b)), hydration 6 (fig. 9(c)) and hydration 7 (fig. 9(d)). All these reactions took place in airflow conditions (cf. table 3) similar to the first hydration (fig. 8). As noted above, for technical reasons, these hydrations occurred in different advancement ranges and were uncompleted.

First, we note that like for the first hydration, the subsequent hydrations presented similar temperature plateaus at around $33.5^{\circ} \mathrm{C}\left( \pm 2^{\circ} \mathrm{C}\right)$. Although this temperature plateau was less clear-cut than for hydration 1 (fig. 8), no significant changes were observed in its value over successive cycles. Secondly, hydrations 2 and 4 presented a similar temperature time course to the first one: the salt temperatures decreased successively with the progress of the reaction (from $\mathrm{X}_{g}=0.3$ ), from the plateau, towards the inlet airflow temperature $\left(25^{\circ} \mathrm{C}\right)$. This indicates that a reaction front moved though the reaction layer.

For hydrations 6 and 7, no such successive temperature changes were observed. We note that for hydration 7 , the lower temperatures can also be explained by the usual fall in the reaction rate at the end of hydration [34, 37]. This change in the temperature time course is not indicative of a disturbance and degradation of the reactive bed, but can be explained by the reactive bed heterogeneity caused by uncompleted reactions over the successive cycles.

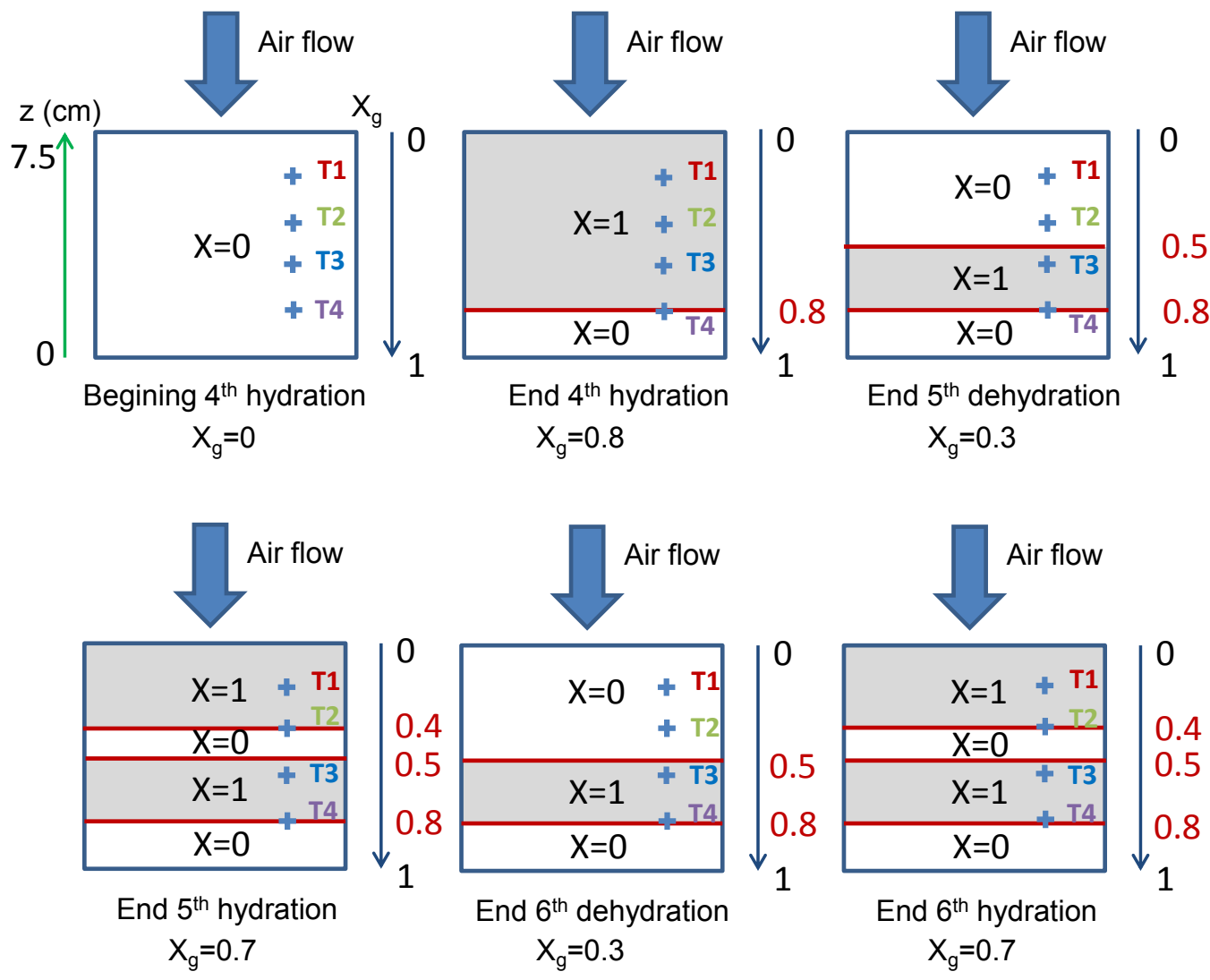

Figure 10: Sharp front evolution inside a reactive bed during the $4^{\text {th }}, 5^{\text {th }}$ and $6^{\text {th }}$ cycles. 
Assuming that the hydration takes place at a sharp reaction front moving in the airflow direction, and taking into account the overall advancement at the end of each reaction, we can plot the location of the reaction front and the fully reacted and unreacted parts of the beds. This is done for cycles $4-6$ in fig. 10 . Hydration 4 starts at $\mathrm{X}_{g}=0$, the salt bed is initially perfectly homogeneous, and the salt is fully dehydrated. At the end of hydration $4\left(\mathrm{X}_{g}=0.8\right)$, a bottom layer $(0.2)$ is unreacted. Similarly, as the next dehydration is also uncompleted $\left(\mathrm{X}_{g}=0.3\right)$, a layer of fully reacted salt appears above the previous unreacted one.

Thus over partial successive cycles, the initial and final states of hydration 6 are composed of a series of hydrated and dehydrated salt layers. The same effect occurs during hydration 7. Similar results, not presented here, have been obtained for the dehydration case [7]. Hence according to the initial state of the salt bed, and the location of thermocouples compared with the fully reacted and unreacted layers, the measured temperature profiles can change, and these changes are not representative of any change in the reaction kinetics, transfer within the bed or bed texture.

Thus the analysis of the thermal response of the thermocouples distributed in the bed bulk is not a reliable way to locate the reaction front and detect any change in kinetics or transfer within the reactive bed over successive cycles. However, on the simplifying assumption of a sharp reaction front defining these layers, we cannot go further in the analysis of each thermocouple time course. We also note that this pattern can be accentuated by boundary effects due to heat losses to the air collector and ambient air. These boundary effects can be significant during the dehydrations, where temperature gradients are steeper.

The analysis of the local data from the prototype experiment shows the presence of a reaction front, moving through the salt bed with the moist airflow. The reaction front is characterized by successive changes in the salt bed temperature (along the moist air flow axis), from a plateau temperature (corresponding to the reaction equilibrium temperature), to the inlet moist air temperature.

Knowing the reaction front position using temperature measures could be a simple way to determine the overall reaction advancement to help manage a large-scale thermochemical storage system. However, knowing the initial state of the reactive bed is important for an analysis of the local temperature time course. Thus if the initial bed is uneven, no conclusions can be reliably drawn from temperature profiles on the kinetics or transfer time course over successive cycles.

\section{Conclusion}

This work looks at open thermochemical systems for high density long-term (seasonal) storage of energy, especially solar. We focused on the local analysis of the reactive bed behavior in such a system during hydration/dehydration reactions. The mass transfers and the reaction kinetic time course within the reactive porous bed were examined. Three state variables were analyzed: overall reaction advancement, pressure drop across the salt bed (inversely proportional to bed permeability) and local bed temperature. For this purpose, two different experimental set-ups, a small scale characterization bench and a large scale prototype, were used. In this way a local analysis of the reactive bed behavior was performed at different scales and for several reactive bed implementations.

The salt bed temperature analysis evidenced a reaction front moving through the reactive layer from the inlet of moist air to its outlet. This reaction front was observed in both hydration and 
dehydration reactions. It was characterized by a plateau followed by a temperature change (increase/decrease) in dehydration/hydration from the reaction equilibrium temperature to the moist air inlet temperature. Hence from temperature measurements we could determine the front position simply, and thereby the overall reaction advancement. However, the thermal response depends on the initial profile of local advancement in the reactive bed, and local temperatures are not representative of the reaction front localization if the initial advancement profile is uneven.

Analysis of mass transfer through the reactive bed shows that reactive bed permeability strongly changed with reactive bed density and during the reaction. For the reactive pair studied, the permeability changed by three orders of magnitude (from $10^{-9}-10^{-12} \mathrm{~m}^{2}$ for $\mathrm{k}_{0}$ ) when the energy density ranged across the target values for long-term storage applications $\left(300-600 \mathrm{kWh} \cdot \mathrm{m}^{-3}\right)$. Additionally, during hydration/dehydration, the permeability decreased/increased by up to two orders of magnitude. This permeability time course was asymmetric: as $\mathrm{f}\left(1 / \mathrm{X}_{g}\right)$ in hydration and as $\mathrm{f}\left(\mathrm{X}_{g}\right)$ in dehydration. The $1 / \mathrm{X}_{g}$ evolution was consistent with a reaction front moving along the air flow axis, and corresponded to the permeability change of a series combination of a fully hydrated layer $(\mathrm{X}=1)$ and a dehydrated layer $(\mathrm{X}=0)$. In the dehydration case, the reactive layer configuration and time course was more complex, and could involve possible diffusion paths through the reactive bed created by the dehydration, leading to a combination of hydrated and dehydrated layers in parallel. Thus the thermochemical reaction leads to significant local changes in the reactive bed properties. These changes would have to be taken into account when designing or modeling systems of fixed bed thermochemical reactors

Reactive bed behavior is an important factor in open thermochemical storage system design and modeling, and so needs thorough analysis.

\section{Acknowledgement}

We thank the French National Research Agency (Agence Nationale de la Recherche) for their financial support of the project ESSI (ANR-08-STOCK-E-04).

\section{References}

[1] International Energy Agency, World energy statistics, Tech. Rep. report n 978-92-64-12413-4 (2011).

[2] K. E. N'Tsoukpoe, H. Liu, N. Le Pierrès, L. Luo, A review on long-term sorption solar energy storage, Renewable and Sustainable Energy Reviews 13 (9) (2009) 2385-2396. doi:10.1016/ j.rser.2009.05.008.

[3] J. Xu, R. Z. Wang, Y. Li, A review of available technologies for seasonal thermal energy storage, Solar Energy 103 (2014) 610-638. doi:10.1016/j.solener.2013.06.006.

[4] P. Pinel, C. A. Cruickshank, I. Beausoleil-Morrison, A. Wills, A review of available methods for seasonal storage of solar thermal energy in residential applications, Renewable and Sustainable Energy Reviews 15 (7) (2011) 3341-3359. doi:10.1016/j.rser.2011.04.013. 
[5] B. Michel, N. Mazet, P. Neveu, Experimental investigation of an innovative thermochemical process operating with a hydrate salt and moist air for thermal storage of solar energy: Global performance, Applied Energy 129 (2014) 177-186. doi:10.1016/j.apenergy.2014.04.073.

[6] D. Aydin, S. P. Casey, S. Riffat, The latest advancements on thermochemical heat storage systems, Renewable and Sustainable Energy Reviews 41 (2015) 356-367. doi:10.1016/j. rser.2014.08.054.

[7] B. Michel, Procédé thermochimique pour le stockage intersaisonnier de l'énergie solaire: modélisation multi-échelles et expérimentation d'un prototype sous air humide, Ph.D. thesis, PhD Thesis, Université Perpignan Via Domitia, Perpignan (2012).

[8] S. Mauran, H. Lahmidi, V. Goetz, Solar heating and cooling by a thermochemical process. First experiments of a prototype storing $60 \mathrm{~kW}$ h by a solid/gas reaction, Solar energy $82(7)$ (2008) 623-636. doi:10.1016/j.solener.2008.01.002.

[9] H. Lahmidi, S. Mauran, V. Goetz, Definition, test and simulation of a thermochemical storage process adapted to solar thermal systems, Solar Energy 80 (7) (2006) 883-893. doi:10.1016/ j.solener.2005.01.014.

[10] J.-C. Hadorn, Advanced storage concepts for active solar energy—IEA SHC Task 32 2003-2007, in: In proceeding of Eurosun, Lisbon, Portugal, 7-10 October 2008.

[11] P. Tatsidjodoung, N. Le Pierrès, L. Luo, A review of potential materials for thermal energy storage in building applications, Renewable and Sustainable Energy Reviews 18 (2013) 327349. doi:10.1016/j.rser.2012.10.025.

[12] F. Trausel, A.-J. de Jong, R. Cuypers, A Review on the Properties of Salt Hydrates for Thermochemical Storage, Energy Procedia 48 (2014) 447-452. doi:10.1016/j . egypro. 2014. 02.053.

[13] K. E. N'Tsoukpoe, T. Schmidt, H. U. Rammelberg, B. A. Watts, W. K. L. Ruck, A systematic multi-step screening of numerous salt hydrates for low temperature thermochemical energy storage, Applied Energy 124 (2014) 1-16. doi:10.1016/j.apenergy.2014.02.053.

[14] K. Korhammer, M.-M. Druske, A. Fopah-Lele, H. U. Rammelberg, N. Wegscheider, O. Opel, T. Osterland, W. Ruck, Sorption and thermal characterization of composite materials based on chlorides for thermal energy storage, Applied Energy 162 (2016) 1462-1472. doi : 10.1016/ j.apenergy . 2015.08.037.

[15] I. M. Van de Voort, Characterization of a thermochemical storage material, Eindhoven University of Technology Master Thesis.

[16] S. Mauran, H. Lahmidi, V. Goetz, 3rd Intermediate Report, European project no NNE5-200000385, Tech. rep. (2002).

[17] D. R. Lide, CRC Handbook of Chemistry and Physics, CRC Press, 2012.

[18] B. Michel, N. Mazet, S. Mauran, D. Stitou, J. Xu, Thermochemical process for seasonal storage of solar energy: Characterization and modeling of a high density reactive bed, Energy 47 (1) (2012) 553-563. doi:10.1016/j.energy.2012.09.029. 
[19] H. A. Zondag, M. Van Essen, L. Bleijendaal, J. Cot, R. Schuitema, W. Planje, T. Epema, H. Oversloot, Comparison of reactor concepts for thermochemical storage of solar heat, in: In: Proceeding of IRES, 2008.

[20] H. Zondag, V. Van Essen, R. Schuitema, L. Bleijendaal, W. Van Helden, M. Bakker, Engineering assessment of reactor designs for thermochemical storage of solar heat, in: In proceeding of Effstock, Thermal Energy Storage for Energy Efficiency and Sustainability, Stockholm, Sweden, 2009 june 14-17.

[21] A. Solé, I. Martorell, L. F. Cabeza, State of the art on gas-solid thermochemical energy storage systems and reactors for building applications, Renewable and Sustainable Energy Reviews 47 (2015) 386-398. doi:10.1016/j.rser.2015.03.077.

[22] D. Stitou, N. Mazet, S. Mauran, Experimental investigation of a solid/gas thermochemical storage process for solar air-conditioning, Energy 41 (1) (2012) 261-270. doi:10.1016/j. energy.2011.07.029.

[23] N. Le Pierrès, N. Mazet, D. Stitou, Experimental results of a solar powered cooling system at low temperature, International Journal of Refrigeration 30 (6) (2007) 1050-1058. doi: 10.1016/j.ijrefrig.2007.01.002.

[24] A. Fopah Lele, F. Kuznik, H. U. Rammelberg, T. Schmidt, W. K. L. Ruck, Thermal decomposition kinetic of salt hydrates for heat storage systems, Applied Energy 154 (2015) 447-458. doi: $10.1016 / j$. apenergy .2015.02.011.

[25] T. Nagel, S. Beckert, C. Lehmann, R. Gläser, O. Kolditz, Multi-physical continuum models of thermochemical heat storage and transformation in porous media and powder beds-A review, Applied Energy 178 (2016) 323-345. doi:10.1016/j.apenergy.2016.06.051.

[26] D. Jaehning, R. Hausner, W. Wagner, C. Isaksson, Thermo-chemical storage for solar space heating in single-family house, in: In: Proceeding of Ecostock, New Jersey, 2006.

[27] R. De Boer, W. Haije, J. Veldhuis, S. Smeding, Solid sorption cooling with integrated storage: the SWEAT prototype, in: 3rd international heat powered cycles conference - HPC, Larnaca, Cyprus, 2004.

[28] T. Li, R. Wang, J. K. Kiplagat, Y. Kang, Performance analysis of an integrated energy storage and energy upgrade thermochemical solid-gas sorption system for seasonal storage of solar thermal energy, Energy 50 (2013) 454-467. doi:10.1016/j .energy.2012.11.043.

[29] J. Yan, C. Y. Zhao, Experimental study of $\mathrm{CaO} / \mathrm{Ca}(\mathrm{OH}) 2$ in a fixed-bed reactor for thermochemical heat storage, Applied Energy 175 (2016) 277-284. doi:10.1016/j .apenergy . 2016. 05.038

[30] H. Kerskes, Seasonal sorption heat storage, in: DANVAK seminar (solar heating systems Combisystems - heat storage), DTU Lyngby, 2006.

[31] A. Hauer, E. Lävemann, Open absorption systems for air conditionning and themal energy storage, Thermal energy storage for sustainable energy consumption, Netherland: Springer, 2007, p. 429:444. 
[32] F. Bertsch, B. Mette, S. Asenbeck, H. Kerskes, H. Müller-Steinhagen, Low temperature chemical heat storage-an investigation of hydration reactions, in: In: Proceeding of Effstock, Stockholm, Sweden, 2009.

[33] H. Zondag, B. Kikkert, S. Smeding, R. de Boer, M. Bakker, Prototype thermochemical heat storage with open reactor system, Applied Energy 109 (2013) 360-365. doi:10.1016/j . apenergy.2013.01.082.

[34] F. Marias, P. Neveu, G. Tanguy, P. Papillon, Thermodynamic analysis and experimental study of solid/gas reactor operating in open mode, Energydoi:10.1016/j.energy .2014.01.101.

[35] B. Mette, H. Kerskes, H. Drück, H. Müller-Steinhagen, New highly efficient regeneration process for thermochemical energy storage, Applied Energy 109 (2013) 352-359. doi: $10.1016 / j$.apenergy . 2013.01.087.

[36] A. Hauer, Development of a commercial thermal energy storage - From thermodynamics to the final product, in: Eurotherm $n^{\circ} 93$, Bordeaux, 2011.

[37] B. Michel, P. Neveu, N. Mazet, Comparison of closed and open thermochemical processes, for long-term thermal energy storage applications, Energy 72 (2014) 702-716. doi:10.1016/j . energy.2014.05.097.

[38] A. H. Abedin, M. A. Rosen, Closed and open thermochemical energy storage: Energy- and exergy-based comparisons, Energy 41 (1) (2012) 83-92. doi:10.1016/j . energy . 2011.06.034.

[39] A. Fopah-Lele, F. Kuznik, T. Osterland, W. K. L. Ruck, Thermal synthesis of a thermochemical heat storage with heat exchanger optimization, Applied Thermal Engineeringdoi:10.1016/j . applthermaleng.2015.12.103.

[40] G. Tanguy, P. Papillon, C. Paulus, Seasonal storage coupled to solar combisystem: dynamic simulations for process dimensioning, in: In Proceeding of EuroSun, Gratz, Austria, 2010.

[41] Ashrae Handbook: Fundamentals, American Society of Heating, Refrigerating and AirConditioning Engineers, Incorporated, 2009.

[42] Y. Tian, C. Y. Zhao, A review of solar collectors and thermal energy storage in solar thermal applications, Applied Energy 104 (2013) 538-553.

[43] G. Rambaud, Problématique des transferts en milieu poreux réactif déformable pour procédés de rafraîchissement solaire, Ph.D. thesis, PhD Thesis, Université Perpignan Via Domitia, Perpignan (2009). 